\title{
Ao revés
}

\author{
Carla Moreira Kinzo ${ }^{1}$
}

RESUMO: O artigo aproxima dois materiais - o filme Os inconfidentes, de Joaquim Pedro de Andrade, de 1972 e o livro K., relato de uma busca, de Bernardo Kucinski, de 2014 - ao redor de uma ideia da escritura do trauma. Filme e livro, cada um a seu modo e em um tempo histórico distinto, lidam com a escritura possível de uma época traumática, a ditadura civil-militar brasileira.

ABSTRACT: The article approaches two materials - Os inconfidentes, by Joaquim Pedro de Andrade, 1972 and K., relato de uma busca, of Bernardo Kucinski, 2014 - around an idea of the deed of trauma. Film and book, each in their own way and in a different historical time, deal with the possible writing a traumatic time, the Brazilian civil-military dictatorship.

PALAVRAS-CHAVE: Joaquim Pedro de Andrade; Bernardo Kucinski; Ditadura Civil-Militar brasileira.

KEYWORDS: Joaquim Pedro de Andrade; Bernardo Kucinski; Brazilian civil-military dictatorship.

"O processo da memória no homem faz intervir não só a ordenação de vestígios, mas também a releitura desses vestígios"

Changeaux in Le Goff, 2003, p. 420

"Pintar o mar ao revés". É a essa imagem que Carlo Ginzburg chega ao final do primeiro capítulo de seu livro Olhos de madeira, no qual faz um percurso sobre a ideia de estranhamento na Literatura. Nele, Ginzburg parte do primeiro formalismo russo (“Sabemos como é feita a vida, e até como são feitos Dom Quixote e o automóvel" - é o trecho da carta que Victor Chklovski envia a Roman Jakobson em 1922, que abre o capítulo "Estranhamento"), passa pelos estudos de Chklovski sobre o papel da arte como instrumento para dar a ver percepções automatizadas, pelo uso do estranhamento como expediente deslegitimador em Tolstoi, para chegar - e até aqui fomos propositalmente breves, já que nos interessa essa imagem final - a Proust. Se em Tolstoi, Ginzburg

\footnotetext{
${ }^{1}$ Doutoranda no Programa de Estudos Comparados de Literaturas de Língua Portuguesa FFLCH USP.
} 
recapitula uma tradição intelectual ligada à busca do "verdadeiro princípio causal como antídoto às falsas representações" (GINZBURG, 2009, p. 36), em Proust, ele afirma, o objetivo parece ser oposto: há um desejo de "proteger o frescor das aparências contra a intrusão das ideias, apresentando as coisas 'na ordem da sua percepção', ainda não contaminadas por explicações causais" (GINSZBURG, 2009, p. 36).

É essa a imagem do mar ao revés. Ao invés de nos apresentar as coisas em sua ordem lógica, começando pela causa - ou desejando alcançá-la -, a imagem ao avesso nos mostra primeiro o efeito, revelando a ilusão que nos instiga, que nos atrai. Em $\grave{A}$ sombra das raparigas em flor, da imagem do mar nos quadros de Elstir, Proust diz:

\footnotetext{
Num quadro retratando Balbec num dia tórrido de verão, uma reentrância do mar, encerrada em muralhas de granito rosa, parecia não ser o mar, que começava mais longe. A continuidade do oceano era sugerida apenas pelas gaivotas que, volteando sobre o que para o espectador parecia ser pedra, absorviam, ao contrário, a umidade das águas. (PROUST in GINZBURG, 2009, p. 37)
}

Esse "dorso da imagem”, que recusa a ideia lógica causal ao se mostrar, parece ser, a nosso ver, um possível ponto de aproximação entre dois materiais, produzidos em diferentes décadas: Os inconfidentes, filme de 1972 de Joaquim Pedro de Andrade e o livro $K$, de Bernardo Kucinski, de 2011, tentam dizer de um passado impossível de ser remontado em seus múltiplos cacos: a ditadura civil-militar iniciada em 1964 no país. Importante pensar que o filme de Joaquim Pedro dizia dos acontecimentos enquanto pessoas sumiam - Os inconfidentes foi lançado apenas dois anos antes do desaparecimento de Ana Kucinski, a "destinatária inexistente" a quem são enviadas cartas de bancos, mais de três décadas depois. $K$. é escrito sob a impressão fantasmática que mantém o nome de Ana no rol dos vivos, que não permite que o passado passe - e que parece tornar ainda mais impossível que se fale dele sob uma ideia de totalidade.

Cada material, a seu modo, parece costurar uma "imagem ao revés", de que falaremos mais detidamente a seguir. Pensamos que talvez apenas assim - encarando a impossibilidade de dizer, seja tomando para si essa ideia reversa, seja olhando os fragmentos do tempo como fragmentos de fato - seja possível apreender o que escapa dessa totalidade pela ficção. 


\section{Os inconfidentes}

Foi em 1972 que Joaquim Pedro filmou Os inconfidentes, seu terceiro longa. O ano marcava os 150 anos da independência do país e o filme, misturando em seu roteiro os relatos dos Autos da Devassa contra os acusados de traição à corte portuguesa, poesias de integrantes da conjugação mineira e textos da poeta Cecília Meireles, propunha a configuração de um retrato, feito de ambiguidades, dos líderes da inconfidência que, antes de chegarem à ação, acabaram sufocados.

Tomás Antônio Gonzaga (Luis Linhares), Alvarenga Peixoto (Carlos Kroeber), Cláudio Manoel da Costa (Fernando Torres) e Bueno Silveira (Paulo César Peréio) costuram seus relatos no filme ora num tecido épico, ora no jogo dramático, revelando o arco irônico que os levou de cidadãos destacados, que se opuseram à derrama de maneira inflamada, a covardes depois de presos pela autoridade colonial.

É preciso dizer que nesse arco ao longo do filme, nenhum deles é poupado - nem mesmo Tiradentes - de um olhar sobre como essa sociedade, já ali, se erguia sobre o irreparável: a escravidão. Presença incansável, ainda que marginal e algo fantasmática (os negros não têm voz, não são sujeitos, mas objetos - inclusive dessas figuras sediciosas), ela estará ali, sempre, a "moldurar" os conflitos que se dão no centro das cenas, e arrastando, dada a força centrípeta que possui, qualquer coisa de perturbadora dessas margens para dentro de muitos dos planos do filme.

É assim que, a nós, espectadores, não é permitido esquecer que há algo ainda mais subterrâneo que se move sob aqueles arranjos políticos - armados alegoricamente por Joaquim Pedro para conseguir falar de outro momento traumático que se dava enquanto o filme era realizado: a ditadura civil-militar brasileira.

\section{Mnemon rebelde}

Na mitologia, mnemon é o "servidor de um herói que o acompanha sem cessar, para lembrar-lhe de uma ordem divina cujo esquecimento traria a morte”. (LE GOFF, 2003, p. 433). Os mnemones, nos lembra Le Goff, verdadeiros arquivistas que são, servem às cidades como magistrados encarregados da conservação na memória do que é útil para a vida religiosa e jurídica. Se pensarmos no cineasta como uma espécie de "mnemon contemporâneo", atravessado, ele também, pela experiência do trauma histórico, o que ele não nos deixa esquecer é aquilo que perturba a vida organizada da cidade, duvidando Revista Crioula USP, ${ }^{\circ}$ 17, junho de 2016 
de uma história que possa ser alinhavada perfeitamente em causa e consequência. No ensaio "A obra de arte na era de sua reprodutibilidade técnica", Walter Benjamin (2013) fala do abalo violento, capaz de tirar-nos da história e nos jogar no campo de forças do choque, gerado pela técnica reprodutiva (que nos desliga do campo da tradição). Para Benjamin, o cinema seria a técnica correspondente à incorporação do choque no campo estético, já que interfere profundamente no aparato perceptivo do homem. Interessante pensar no cineasta, aqui, como um mnemon rebelde, arquiteto de uma arte que se funda no choque da recepção, repetindo incansavelmente fotogramas para deslocar imagens traumáticas e perfurar a capa encobridora do real, que a naturaliza. Esse mnenon contemporâneo estranha os fatos, fazendo uso de um campo estético fundado no choque para deslocar imagens encobertas, seja do próprio cinema (e não à toa Joaquim Pedro usa imagens de arquivo de comemorações oficiais da independência em seu filme), seja de seu próprio tempo (e a sequência sobre a qual escolhemos falar nesse filme faz o salto nele, no tempo, assim que Tiradentes salta, da forca, para a ano em que filmava $O s$ inconfidentes).

Esse deslocamento de imagens se faz, no filme, pela recusa da cadeia lógica de acontecimentos; pelo desejo de mostrar no lugar de explicar (ou encadear) os fatos; no amparo dos vestígios, daquilo que resta. Da pesquisa para o roteiro do filme, Joaquim Pedro de Andrade diz que "toda a história da conspiração está vista a partir da cadeia” e que, portanto, eles tinham "de um lado, um tipo de depoimento um pouco deformado pelo medo, pela pressão do interrogatório. De outro lado a poesia que obedecia em parte a esta motivação, mas tinha um olho muito fixo na posteridade". ${ }^{2}$ Assim, esses vestígios, esses documentos que recontam a inconfidência vista da cadeia, são reconfigurados pelo filme de modo a não perderem sua natureza "fraturada", pois permanecem como vestígios restos do que foi - em cena. A própria ideia de posteridade presente nas poesias de Gonzaga, por exemplo, é material dessa costura de pontos de vista, que inclui o que as palavras não encerram, como o medo deformador de que fala Joaquim Pedro em seu depoimento sobre o material base para o roteiro do filme. É desta maneira, por não nos darem nada que seja inteiro, por se mostrarem sincopados, rompidos, que eles apontam para um lugar fora deles mesmos - e daquilo que o cineasta enquadra efetivamente com

\footnotetext{
${ }^{2}$ Do encarte do filme (box comemorativo, pela Filmes do Serro), em que há excertos de entrevistas concedidas por Joaquim Pedro para o Jornal do Brasil (15/4/1972); na Revista do Brasil (número especial dedicado ao bicentenário da Inconfidência Mineira) e o texto "Depoimento Especial", em $O$ cinema de Joaquim Pedro de Andrade (publicado em 1/8/1976).
}

Revista Crioula USP, $n^{\circ}$ 17, junho de 2016 
sua objetiva - mas que é capaz de dizer, ainda que sem palavras, do que estava acontecendo naqueles anos ao redor da produção do filme.

\section{Tempo}

A memória coletiva é uma forma importante na luta das forças sociais pelo poder.

Segundo Le Goff,

Tornar-se senhores da memória e do esquecimento é uma das grandes preocupações das classes, dos grupos, dos indivíduos que dominam as sociedades históricas. Os esquecimentos e os silêncios da história são reveladores destes mecanismos de manipulação da memória coletiva. (LE GOFF, 2003, p. 422)

Tendo em vista que "história" pode ser entendida não apenas como o conjunto dos acontecimentos decorridos, mas também "como conjunto dos discursos sobre esses acontecimentos" (RICOEUR, 2001, p. 362), realizar uma “torção" nesse discurso pode ser um caminho para tentar dar a ver o que não pode ser esquecido, ou repetido. Ricouer propõe, ao passar por Heidegger, uma reflexão em torno da ideia de temporalidade que leva em conta uma relação com o futuro: ou seja, que a ideia de uma "preteridade" seja posta em relação dialética com outra, de "futuridade". Assim, nesse jogo, a relação da temporalidade com o futuro ilumina a sequência das demais determinações temporais da experiência histórica.

Se os esquecimentos e os silêncios da história revelam os mecanismos de manipulação da memória coletiva, jogar luz neles é, talvez, propor um novo futuro a partir do passado. A sequência final de Os inconfidentes, que trata do enforcamento de Tiradentes, é exemplar desse mecanismo, já que, nele, há duas instâncias que narram o acontecimento e que se mostram no corte direto de um plano a outro, no instante em que a personagem cai, e que desloca a ação do tempo do filme para aquele em que o espectador se encontra, sem mediações.

Nesse pulo no tempo, no instante em que, no plano, é possível ver o "presente no passado", há uma proposta de reconfiguração desse "olhar para trás" que o filme faz a partir de uma visada para frente - e, sobretudo, para o agora. É como se, como pontuamos a partir de Ricoeur, houvesse a constituição de uma nova temporalidade a partir do filme, na qual aquele instante em que vemos os anos 70 assistirem ao enforcamento de 
Tiradentes pudesse ter a potência de iluminar toda a cadeia temporal erguida até aquele momento, a partir de uma nova ótica.

\section{Os inconfidentes: sequência final}

Façamos novamente o caminho dessa sequência que encerra o filme: Tiradentes está pronto para sua sentença. E o carrasco, um escravo, depois de proferidas as palavras de ordem da colônia, coloca a corda ao redor de seu pescoço (essa sequência do enforcamento é entrecortada por outras cenas que mostram o que aconteceu aos demais inconfidentes). As primeiras notas de Aquarela de Brasil, de Ari Barroso, começam a tocar, em um arranjo que despreza o tom grandiloquente de suas primeiras gravações: aqui, ela soa leve, alegre - irônica. É então que Tiradentes é empurrado. A câmera, que antes via-o debaixo, lugar daqueles que assistiram a sua morte, está agora atrás dele. E do carrasco, que depois de empurrá-lo, pula na corda, sobre seu corpo, para garantir o sufocamento. É no instante do salto que faz seu corpo pender no ar, no alto da forca, que há o deslocamento claro de uma imagem, de uma "capa encobridora do real" que mencionamos no início desse trabalho. Não é apenas Tiradentes que salta, mas também o tempo: e o espectador "cai" na cidade de Ouro Preto, no ano em que o filme era realizado. Assim, nessa sequência, o espectador é levado, pela posição da câmera em uma e outra cena, a experimentar não apenas dois pontos de vista diversos (de espectador da execução e do sentenciado), mas dois tempos diferentes - e tudo o que há de inominável entre um tempo e outro, entre uma e outra posição no espaço. Vale relembrar que filme nos fornece muitos vestígios do inominável em nossa história também nas bordas dos planos, como já dissemos, quando coloca o escravo, uma vez mais, ao redor do da cena, em sua margem - silencioso, com uma máscara branca a cobrir-lhe o rosto - também realizando o salto. Quase "invisível”, mas inesquecível.

$\mathrm{Na}$ sequência final ainda, depois dos aplausos, a Aquarela do Brasil invade imagens de arquivo em preto e branco, com militares marchando sobre a cidade, sob a voz de um narrador solene, que afirma: "Ouro Preto, a antiga capital de Minas Gerais, cidade-monumento que é um relicário de tesouros e arte e das mais belas tradições de nossa formação histórica, transforma-se na data de 21 de abril em cenário de imponentes celebrações cívicas".

Destacamos, no discurso desse narrador, as expressões "monumento", "relicários", "tesouros", "tradições de nossa formação histórica". E mais uma vez Revista Crioula USP, $\mathrm{n}^{\circ}$ 17, junho de 2016 
voltamos a Le Goff, para pensar a ideia da pedra como suporte para a inscrição de uma memória da autoridade, na criação das instituições de poder. Se a pedra e o mármore serviam - o autor afirma - como suporte à memória, e "os arquivos de pedra acrescentavam à função de arquivos propriamente ditos um caráter de publicidade insistente, apostando na ostentação e na durabilidade dessa memória lapidar e marmórea" (LE GOFF, 2013, p. 428), Joaquim Pedro de Andrade, "mnemon rebelde" que é, recusa à cidade essa memória-monumento, marmórea. Sua inscrição no filme - ou uma reflexão sobre ela - se dá sob corpos, ou melhor, sob o corpo de um homem. E esse corpo pereceu, não há mais; não foi enterrado, não tem uma lápide sobre ele. É ao lado das pedras de Ouro Preto, dos monumentos que foram erguidos que esse corpo jaz, invisível: e sua invisibilidade carrega uma porção da história não dita, reconfigurada pelo tempo, já que tem potência de dizer, ainda, do momento presente. A cidade de Ouro Preto, no filme, é mais do que uma cidade-monumento, pois; ela é, também, uma cidade da memória que não se vê, mas que se sabe.

Às cenas de arquivo, em que o narrador segue exaltando "os grandes heróis do passado", alternam-se fragmentos de uma sequência em que um machado corta um pedaço de carne: alusão a esse corpo - matéria que evoca, uma vez mais, a violência que não se põe em palavras sem que algo dela se perca.

As palavras ditas, ao final do filme, ficam à cargo desse narrador pomposo, afirmando suas verdades sobre as cenas remontadas (em que passado e presente são reconfigurados pela montagem alternada), sempre ao som da Aquarela do Brasil. E então, algo ali se diz, sem palavras. Há os aplausos dos civis na sequência preto e branca e, depois, a imagem da carne sangrenta sobre a qual voam moscas: e o filme acaba.

\section{Tempos}

Vagamos, no filme, do passado para o presente, da coisa encenada para a informação oficial, da violência da história para uma festa. É assim que o filme se revela ao espectador como uma pergunta, como imagem para ser lida em pelo menos dois planos: inconfidência e ditadura militar, passado e presente, imagem e discurso. É no caminho entre uma coisa e outra, entre um plano e outro que o filme se constitui, que rememora uma tentativa, frustrada de saída, de libertação do país (sem deixar de incluir nessa rememoração os festejos dos 150 anos de independência). É assim que $O s$ inconfidentes lança algumas perguntas, na imagem do salto: éramos independentes de 
fato, após a independência? A história se repetia? Das celas dos inconfidentes - e das margens em que vagueiam os escravos no filme - coloca-se a pergunta: aqueles que sonhavam com a liberdade não estavam já, muito antes de se darem conta das grades, vivendo em uma prisão?

Acreditamos que Joaquim Pedro realize, desta maneira, uma espécie de desvio, de deslocamento na narrativa do filme, a partir de uma imagem ao revés - um salto que, ao ressignificar a sequência das cenas que a antecedem, parece tanger o inominável. Em $K$., escrito muitos anos depois, muitas das questões, ainda que repostas e que não tenham sido efetivamente superadas, são recolocadas. Vejamos.

\section{Um modo oblíquo de falar}

Em K., relato de uma busca, desde a epígrafe, "Caro leitor: tudo neste livro é invenção, mas quase tudo aconteceu" (KUCINSKI, 2014, p. 8), há uma percepção das figuras fantasmáticas que movem o livro - movem o pai, subjetividade fraturada pela busca inútil (subjetividade que é, também, coletiva); movem a trama, que sabe que não pode apreender uma totalidade a partir dessas fraturas e assume uma composição em "mosaico"; movem a própria busca do pai, que se desdobra a partir de Ana. E Ana é uma dessas figuras fantasmáticas, mas não a única.

A busca de K. passa por quatro momentos no livro que marcam essa ideia de figuras ausentes de que falamos: a busca pela filha, Ana, é uma; a busca pelo corpo da filha, outra; a busca de uma lápide, mais uma; a busca pelos fatos (a que a personagem K. não terá acesso - ou mesmo nós, leitores, que ainda sabemos mais do que ele).

O primeiro capítulo do livro marca o estranhamento que apresentamos no início desse trabalho quando nos apresenta o efeito - um deles - daquela história de desaparecimento, sem poder nos dizer com precisão sua causa, sua cadência lógica de explicação. Cartas chegam para Ana Kucinski na casa de seu irmão - e como ou por que isso acontece, o narrador não pode nos dizer. O fato é que essas cartas falam, de forma oblíqua, de um esquecimento progressivo desse passado que, ainda que esquecido (ou justamente por isso), não passa, pois mistura os nomes de seus mortos àqueles dos vivos. O nome como um fantasma; o esquecimento, a recordação como um fantasma.

É por meio de uma série de fragmentos que a trama em $K$. se estrutura, feito um mosaico, para dar a ver sua impossibilidade de compreender plenamente uma totalidade. Eis mais um dado de estranhamento que o livro apresenta: pelos pontos de vista diversos, Revista Crioula USP, ${ }^{\circ}$ 17, junho de 2016 
os capítulos, ainda que proponham uma continuidade temática, não podem nos dar uma continuidade temporal. E é assim que ele narra a impossibilidade de saber da morte de Ana, fechando o círculo da tragédia de K. - já que o que acontece se dá independente de suas ações. O leitor é um cúmplice do terror que cerca a personagem e saberá o que ela jamais poderá saber.

Esse círculo trágico - e aqui está a dimensão coletiva de K. - se dá, também, historicamente, já que, uma vez que o passado não passa (não há corpos, ou punição de responsáveis, ou revelação dos fatos), ele invade o presente, que não se abre para o futuro. Mesmo o tempo verbal na narrativa do livro alterna essas vozes no presente e no pretérito, acentuando a ideia de mosaico em sua composição: e essa mistura de tempos diz de uma invasão do passado no presente, de uma impossibilidade de seguir narrando sem que se diga dessa fratura, sem que se assuma essa mistura de vozes, tempos, pontos de vista, cenas. Ainda assim, há uma marca na mistura: na história da busca de K. pela filha, há uma zona de indistinção entre narrador e personagem, que revela a voz que narra como alguém que conhece de perto a história de K. Nas demais personagens, por sua vez, há uma tendência em mostrar a narrativa pelo viés do personagem focalizado - e é assim que o leitor toma conhecimento daquilo que K. não poderá saber. Não há, dessa forma, uma narração que tudo sabe, uma chave de verdade - há, sim, dúvida sobre a capacidade da narrativa em dizer uma verdade, qualquer uma, sobre o que quer que seja.

Ao contrário do narrador onisciente, do "Deus onisciente com o qual se poderia comparar a maioria dos romancistas oitocentistas" (GINZBURG, 2009, p. 39), em K., há motivações ocultas nas personagens que se movem no romance, mas que deixam rastros, vagas impressões, como "o mar pintado ao revés" de que fala Proust, que nos dão pistas, algo a decifrar, algo seguir, algo a tentar restaurar.

Ainda que por diferentes caminhos, há o desejo de dizer o mundo sem uma explicação causal, estranhando-o, pois, solicitando um empenho decifrador, tanto em $O s$ inconfidentes (que se faz no espaço entre dois planos no tempo), quanto em $K$., relato de uma busca (em sua composição fragmentada em tempo, espaço, vozes). Ou ainda, mais do que um desejo, talvez essa seja a única maneira de por esse mundo em alguma palavra.

Quando afirma que "mesmo supondo-se que a guerra seja científica, ainda assim, seria preciso pintá-la como Elstir pintava o mar, ao revés" (PROUST in GINZBURG, 2009 , p. 40), Proust parece nos fornecer uma chave - ainda que ela não abra todos os cadeados da história - de aproximação desses materiais de que tratamos nesse trabalho. Pois mesmo supondo-se que a história seja científica (parafraseando Ginzburg no fim Revista Crioula USP, nº 17, junho de 2016 
desse primeiro capítulo de Olhos de madeira), para tentar escaparmos da condenação sisífica de repeti-la, urge pintá-la ao revés.

\section{Referências}

\section{Livros}

BENJAMIN, Walter. A obra de arte na era de sua reprodutibilidade técnica. Porto Alegre: LP\&M, 2013.

GINSZBURG, Carlo. Olhos de madeira. São Paulo: Companhia das Letras, 2009.

KUCINSKI, Bernardo. K., relato de uma busca. São Paulo: Cosac Naify, 2014.

LE GOFF, Jacques. História e memória. Trad. Bernardo Leitão. Campinas: Editora da UNICAMP. 2003.

RICOEUR, Paul. A memória, a história, o esquecimento. Trad. Alain François. Campinas: Editora da UNICAMP, 2001

\section{DVD}

Os inconfidentes. Dir.: Joaquim Pedro de Andrade. 1972, cor, 80 min. 